\title{
Technological Characterization of Lactic Acid Bacteria Isolated from Different Sheep's Milk
}

\author{
L. Ketrouci, F. Dalache, D. Benabdelmoumene ${ }^{1}$, A.A. Dahou, A. Homrani
}

10.18805/ajdfr.DR-230

\begin{abstract}
Background: Technological characterization of lactic acid bacteria isolated from sheep's milk collected in 3 regions in northwestern Algeria.

Methods: During the period from 2018 to 2019, fifty strains of Lactic acid bacteria isolated from samples sheep's milk were evaluated for several technologically-relevant properties: diacetyl and exopolysaccharides production, acidification, proteolytic and lipolytic activity and their antagonist activity against Escherichia coli and Pseudomonas aeruginosa.

Result: The results indicate that among all the isolates only $20 \%$ were distinguished by their production of EPS mainly the genus Leuconostoc. Diacetyl production was observed in $71 \%$ of Lactobacillus, $60 \%$ of Enterococcus and $25 \%$ in Leuconostoc. $94 \%$ isolates showed moderate proteolytic activity. $56 \%$ and $60 \%$ of the strains degraded tween 80 and olive oil respectively for lipolytic activity. Inhibition activity by the cultures LAB was about $82 \%$ and $78 \%$ against $E$. coli and $P$. aeruginosa respectively. No culture supernatants inhibit $P$. aeruginosa, however $18 \%$ of the Enterococcus trains inhibit E. coli. BME1.A2 and BME2.D4 showed their highest acidification capacity developing a very large quantity of lactic acid after $24 \mathrm{~h}$ of incubation, i.e., 7.6 and $8.4 \mathrm{~g}$ lactic acid/L respectively
\end{abstract}

Key words: Antagonist activity, Lactic acid bacteria, Sheep milk, Technological properties.

\section{INTRODUCTION}

Sheep's milk is an interesting raw material because it is rich in nutrients and contains high concentrations of total solids (Balthazar et al., 2017). This product has specific characteristics which make it the noblest milk indeed lipid and protein contents are twice as high as those found in milks of other dairy species (cows and goats).

Lactic acid bacteria (LAB) constitute a highly phylogenetically heterogenous bacterial group, having the GRAS (Generally Recognized as Safe) status because they are nonpathogenic, suitable for technological and industrial processes (Shehata et al., 2016). LAB are ubiquitous in the environment and are considered to be the dominant microbiota in milk and dairy products. Some characteristics of $L A B$, such as acid production, probiotic, proteolysis, lipolysis and autolysis have contributed to their use as starters, and are investigated when selecting these bacteria. Moreover, exopolysaccharides (EPS) production by LAB received increasing attention due to their immunogenic properties (Cuffia et al., 2020). EPS also contributes to the mouth-feel, texture and taste perception of fermented dairy products (Patil et al., 2015).

\section{MATERIALS AND METHODS}

\section{Milk samples, isolation and identification of LAB}

50 strains of $L A B$ were isolated from different samples sheep's milk collected in 3 regions of North-Western of Algeria, namely, three samples sheep's milk from Naâma (BNF1, BNF2 and BNF3), two samples from Mecheria (BME1 and BME2) and two samples from Mascara (BMA1 and BMA2).
Sciences and Technics of Animal Production Laboratory, Abdelhamid Ibn Badis University, Mostaganem, Algeria.

${ }^{1}$ Applied Animal Physiology Laboratory, Abdelhamid Ibn Badis University, Mostaganem, Algeria.

Corresponding Author: L. Ketrouci, Department of Agronomic Science, Specialty of Animal Production and Biotechnology, Faculty of Natural and Life Sciences, Abd El-Hamid Ibn Badis University, Mostaganem. Email: leyla.ketrouci@univ-mosta.dz

How to cite this article: Ketrouci, L., Dalache, F., Benabdelmoumene, D., Dahou, A.A. and Homrani, A. (2021). Technological Characterization of Lactic Acid Bacteria Isolated from Different Sheep's Milk. Asian Journal of Dairy and Food Research. 40(3): 239-245. DOI: $10.18805 /$ ajdfr.DR-230.

Submitted: 17-02-2021 Accepted: 31-03-2021 Online: 22-04-2021

All strains were identified using phenotypic tests and only 18 strains were performed using the MALDI-TOF MS Biotyper (Bruker Daltonik GmbH, Bremen, Germany) (Data not shown). All experiments were performed in the Laboratory of Sciences and Technics of Animal Production, Faculty of Nature and Life Sciences, Abdelhamid Ibn Badis University, Mostaganem, Algeria.

\section{Biotechnological characterization EPS production}

Production of EPS was screened in MSE medium (sucrose $(10 \%)$ after incubation at $30^{\circ} \mathrm{C}$ for $24 \mathrm{~h}$. EPS production was assessed based on the presence of mucoïd strains and are characterized by the formation of large, slimy and sticky colonies (Fguiri et al., 2016). 


\section{Diacetyl production}

Diacetyl production was detected by the Voges Proskauer (VP) reaction. Strains were seeded on MRS medium, incubated at $30^{\circ} \mathrm{C}$ for $24 \mathrm{~h}$. Then, $0.5 \mathrm{~mL}$ of $1 \%(\mathrm{wt} / \mathrm{vol}) \alpha-$ naphthol solution plus $0.5 \mathrm{~mL}$ of $16 \%$ (wt/ vol) sodium hydroxide solution was added to $1 \mathrm{~mL}$ of microbial culture. After 10 minutes, positive result was visualized by a red ring at the top of the culture (Ribeiro et al., 2014).

\section{Evaluation of proteolytic activity}

Proteolytic activity was determined as by De-Almeida et al. (2015). LAB strains were spotted on surface of MRS agar supplemented with $10 \%$ skimmed milk (wt/vol) and incubated at $30^{\circ} \mathrm{C}$ for $72 \mathrm{~h}$. Positive result was indicated by a clear zone around the spots.

\section{Evaluation of lipolytic activity}

Lipolytic activity was determined on solid MRS medium (at $\mathrm{pH} 7$ ) supplemented with different lipid substrates. This activity was detected on MRS devoid of Tween 80 and supplemented with $3 \%$ olive oil. For artificial source, Tween $80(3 \%)$ was used. Plates were inoculated with the corresponding culture in spots and incubated at $30^{\circ} \mathrm{C}$ for $72 \mathrm{~h}$. Lipolytic activity was detected by clear zones surrounding the spots (Hantsis-Zacharov and Halpern, 2007).

\section{Acidification activity}

$200 \mathrm{~mL}$ of skim milk (10\%) were inoculated $(1 \% \mathrm{v} / \mathrm{v})$ with each strain from 16 selected $\angle A B$ and incubated at $30^{\circ} \mathrm{C}$. Titratable acidity was determined by titrimetric method as described by AOAC (2000) and measured at 0, 2, 4, 6, 8, 10, 12 and $24 \mathrm{~h}$. For most samples, $1 \%$ phenolphthalein (1 $\mathrm{g}$ phenolphthalein in $100 \mathrm{~mL}$ ethyl alcohol $95^{\circ}$ ) was added $(0.5 \mathrm{~mL})$ and the sample was titrated with $\mathrm{N} / 9$ sodium hydroxide to the first permanent (30 s) color change to pink. $\mathrm{pH}$ was measured using a $\mathrm{pH}$ meter (PHSJ-3F). Acidity in dairy products is expressed in Dornic degree $\left(1^{\circ} \mathrm{D}=0.1 \mathrm{~g} / \mathrm{L}\right.$ of lactic acid).

\section{Antibacterial activity Agar spot test method}

Selected microorganisms were screened using the agarspot-test method against two pathogen bacteria of test microorganisms Escherichia coli (ATCC 25922) and Pseudomonas aeruginosa (ATCC 27853). LAB strains were spotted on the surface of MRS or $\mathrm{BHI}$ containing $1 \%$ agar, seeded with one of the test microorganisms $\left(10^{8} \mathrm{UFC} / \mathrm{mL}\right)$, and incubated for $24 \mathrm{~h}$ at $37^{\circ} \mathrm{C}$ (Fleming et al., 1975). Results were determined by measuring clear zones of the inhibition.

\section{Agar well diffusion method}

Inhibitory activity was determined, according to Harris et al. (1989). indicator strains: $E$. coli and $P$. aeruginosa were grown in Tryptone Soya Agar (TSA, Himedia) supplemented with $0.6 \%$ Yeast extract for $24 \mathrm{~h}$ at $37^{\circ} \mathrm{C}$. Each pathogen was suspended in $4 \mathrm{~mL}$ of sterile water and standardized to approximately $10^{8} \mathrm{CFU} / \mathrm{mL}$ and $1 \mathrm{~mL}$ was spread on the surface of plate with MRS agar and allowed to absorb. After,
$70 \mu \mathrm{L}$ of cell free supernatant obtained by centrifugation (Sigma 4-16 KS N ${ }^{\circ} 136689$ ) (6000 rpm /10 min at $4^{\circ} \mathrm{C}$ ) from each isolate of $L A B$ in exponential growth phase were placed into wells bored of $5 \mathrm{~mm}$ in diameter in agar plates.

After diffusion of supernatants for $18 \mathrm{~h}$ at $4^{\circ} \mathrm{C}$, plates were incubated for 24 at $37^{\circ} \mathrm{C}$. Inhibitory activity was asset by measuring the dimension of the clear halos.

All experiments of technological properties were performed in triplicate.

\section{Statistical studies}

The data collected was subjected to an analysis of variance (SAS Institute, 2008). A one-way ANOVA analysis was applied to the results obtained from the activities, using the Student-Newman-Keuls test for comparison of the mean values $(P<0.05)$.

\section{RESULTS AND DISCUSSION}

\section{Technological properties}

According to phenotypic identification, Enterococcus genus was the most group frequently isolated from sheep's milk with a predominance of $70 \%$, followed by Leuconostoc with $16 \%$ and Lactobacillus with $14 \%$. The proportions rate of the different bacterial groups are eminently variable from milk to another, in relation to the variety of operating environments (Dahou et al., 2020).

\section{EPS production}

EPS production was observed in only 10 strains isolated mainly from the two milk samples collected in the region of Mascara, BMA1 and BMA2. All strains belonging to the genus Leuconostoc ( $L n)$ and 2 strains belonging to the genus Enterococcus (En) were found to produce EPS with large and sticky colonies (Table 1). Our results corroborate with those described by Maina et al. (2008), who showed that several strains of Leuconostoc ( Ln. mesenteroïdes and $L n$. citreum) are known to produce exopolysaccharides, which are mainly dextran, which is the case of the three species Ln. mesenteroïdes ssp dextranicum (BMA1.A5, BMA2.B1 and BMA2.E2). Also, Patil et al., (2015), showed that $L A B$ isolated from different milk's produced EPS and played important role in improving of flavor and texture of fermented dairy products.

\section{Diacetyl production}

In our study, $56 \%$ of the isolates produced diacetyl (Table 1 ). $71.42 \%$ of the Lactobacillus $(L b)$ produce diacetyl. In agreement with our results, Nikolic et al. (2008) also observed that a high proportion of Lactobacillus paracasei isolated from goat cheeses had the capacity to produce diacetyl. $60 \%$ of the isolates of Enterococcus produce diacetyl. 3 strains were considered as high-level diacetyl producers, Lb plantarum (BNF1.A8) and two strains of Enterococcus (BNF2.B3 and BNF3.B5). However, only 25\% of the Leuconostoc genus strains produce diacetyl. Moreover, Garabal et al. (2008) showed that optionally heterofermentative Lactobacillus produce the highest 


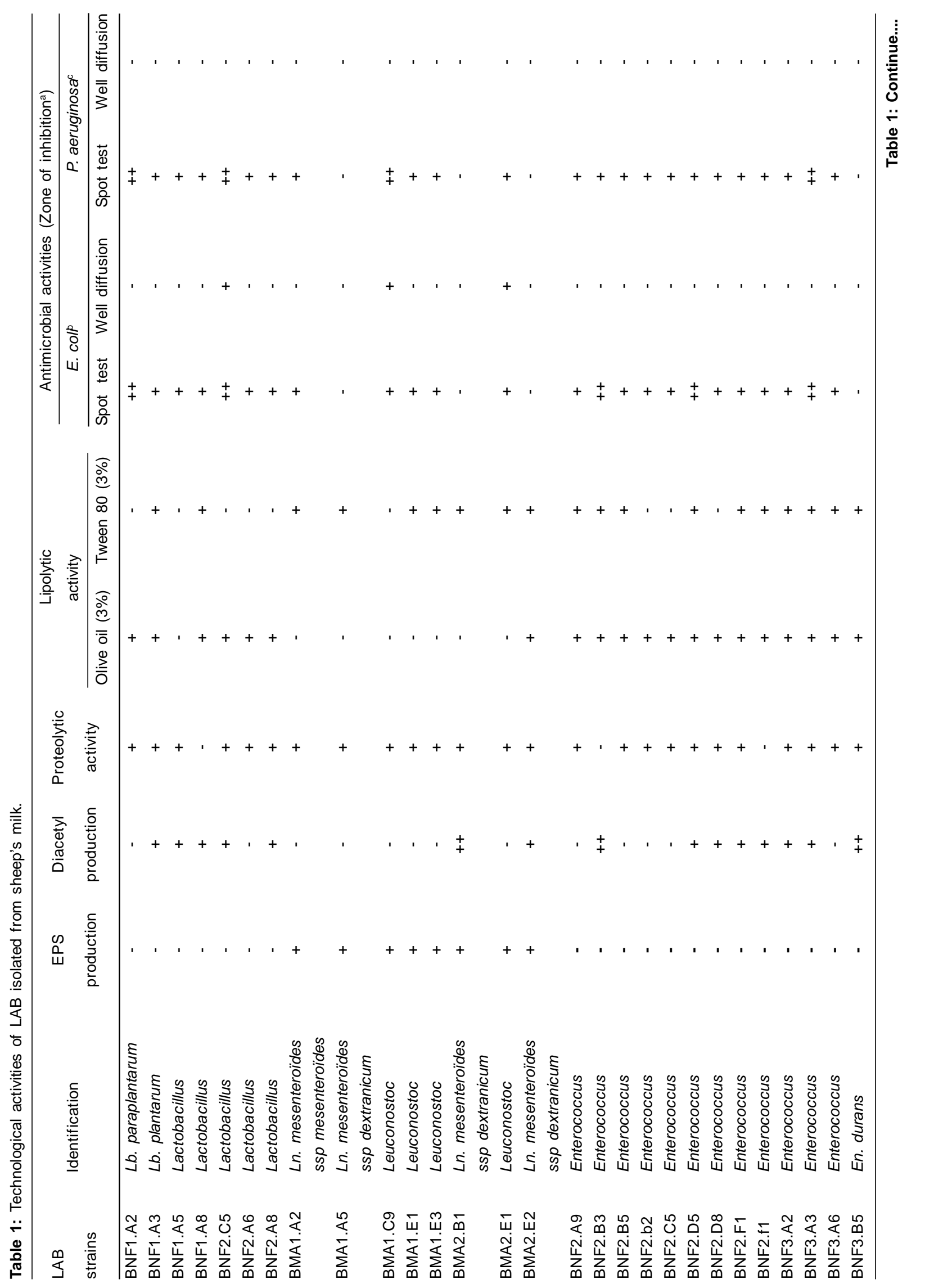




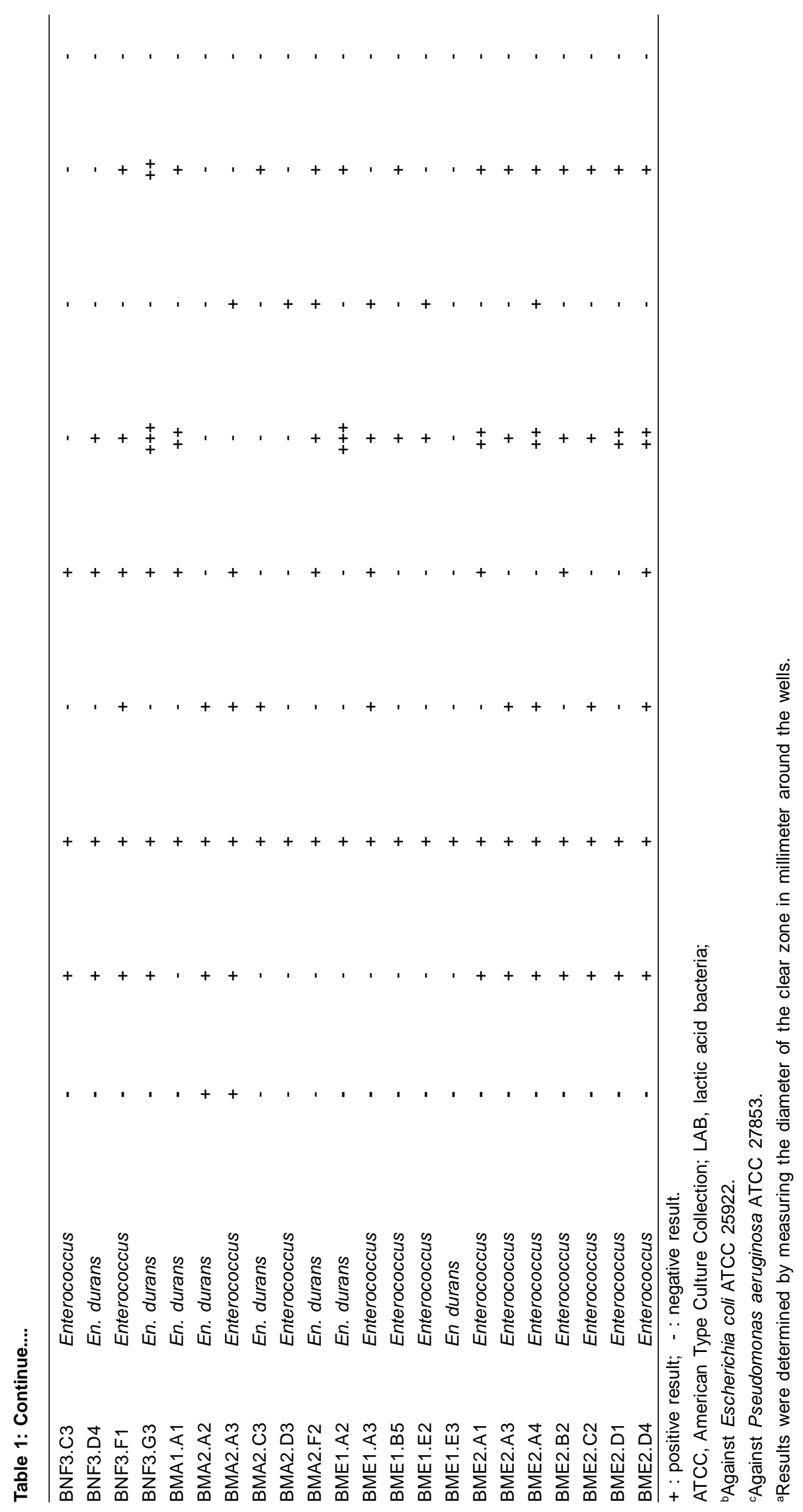


amounts of diacetyl-acetoin in milk, while Leuconostoc produce the lowest amounts of diacetyl-acetoin in acidified milk. This corroborates the results obtained in our study.

\section{Proteolytic activity}

Proteolysis is considered to be the most important biochemical traits during cheese maturation. The isolates studied, hydrolyzed the proteins present in the medium with the exception of strains BNF1.A7, BNF2.B3 and BNF2.f1 (Table 1). All Leuconostocs were positive for the proteolytic activity. Lactobacillus revealed significant proteolytic activity by $6 / 7$ positive results. Our results corroborate with the data reported by Madrau et al. (2006) who showed that Lactobacillus isolated from traditional Pecorino Sardo cheese and goat's milk had significant proteolytic activity. 33/35 of Enterococcal strains are proteolysis positive.

\section{Lipolytic activity}

Lipolytic activity with Tween 80 and olive oil, is pronounced in $56 \%$ and $60 \%$ of the isolates respectively (Table 1). $85 \%$

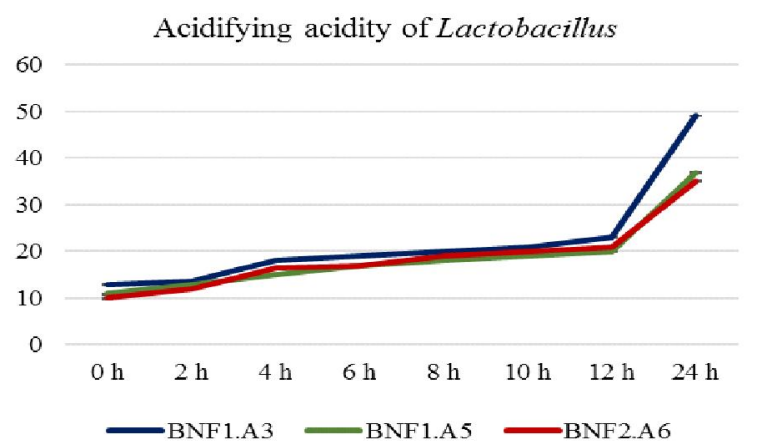

Acidifying activity of Leuconstoc

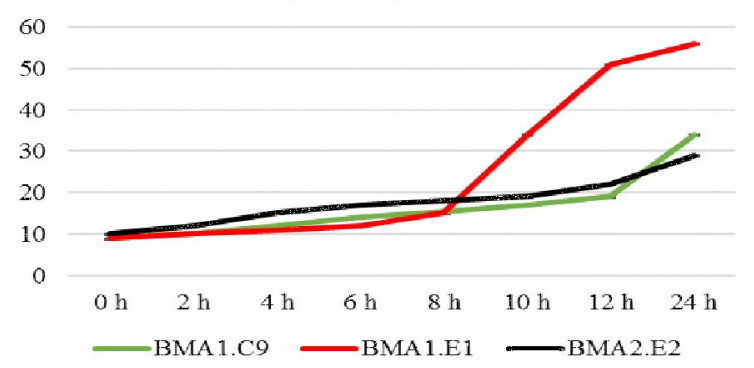

Acidifying activity of Enterococcus

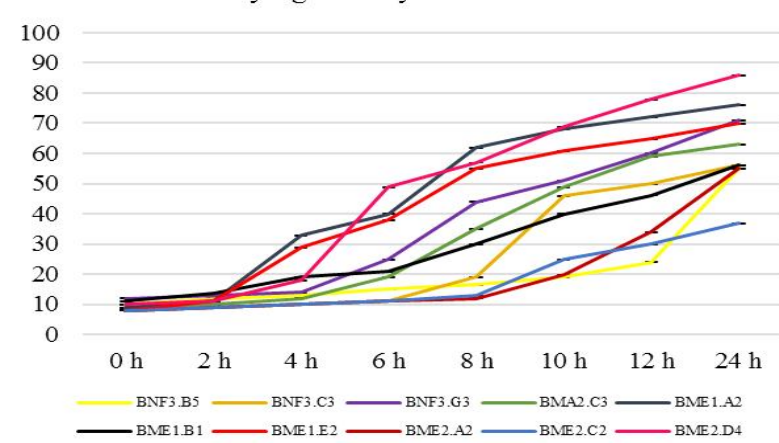

of the Lactobacillus strains degrade olive oil and only $28 \%$ degrade Tween 80. Nieto-Arribas et al. (2010) showed that Lactobacillus isolated from Tenerife cheese and Manchego cheese have no lipolytic activity on tributyrin agar. For Enterococcus genus, 62\% showed positive lipolytic activity with olive oil and $60 \%$ with Tween 80 . Enterococcus are the main genus contributing to the lipolysis of cheese (Giraffa, 2003). For Leuconostoc genus, $87 \%$ strains degraded tween 80 and only $14 \%$ degrade olive oil.

\section{Acidifying power}

The results of acidification activity of 16 strains studied (10 Enterococcus, 3 Lactobacillus and 3 Leuconostoc) revealed differences in acidifying power after $24 \mathrm{~h}$ of incubation (Fig 1).

LAB strains have their ability to ferment lactose into acid lactic (Saha et al., 2017). For Enterococcus genus, all the strains tested gave acidification values between $8.6 \mathrm{~g} / \mathrm{L}$ (BME2.D4. En durans) and $4 \mathrm{~g} / \mathrm{L}$ (BME2.C2. Enterococcus). $\mathrm{pH}$ changes by our Enterococcus strains ranged between 5.78 and 5.01 of incubation (Fig 1).
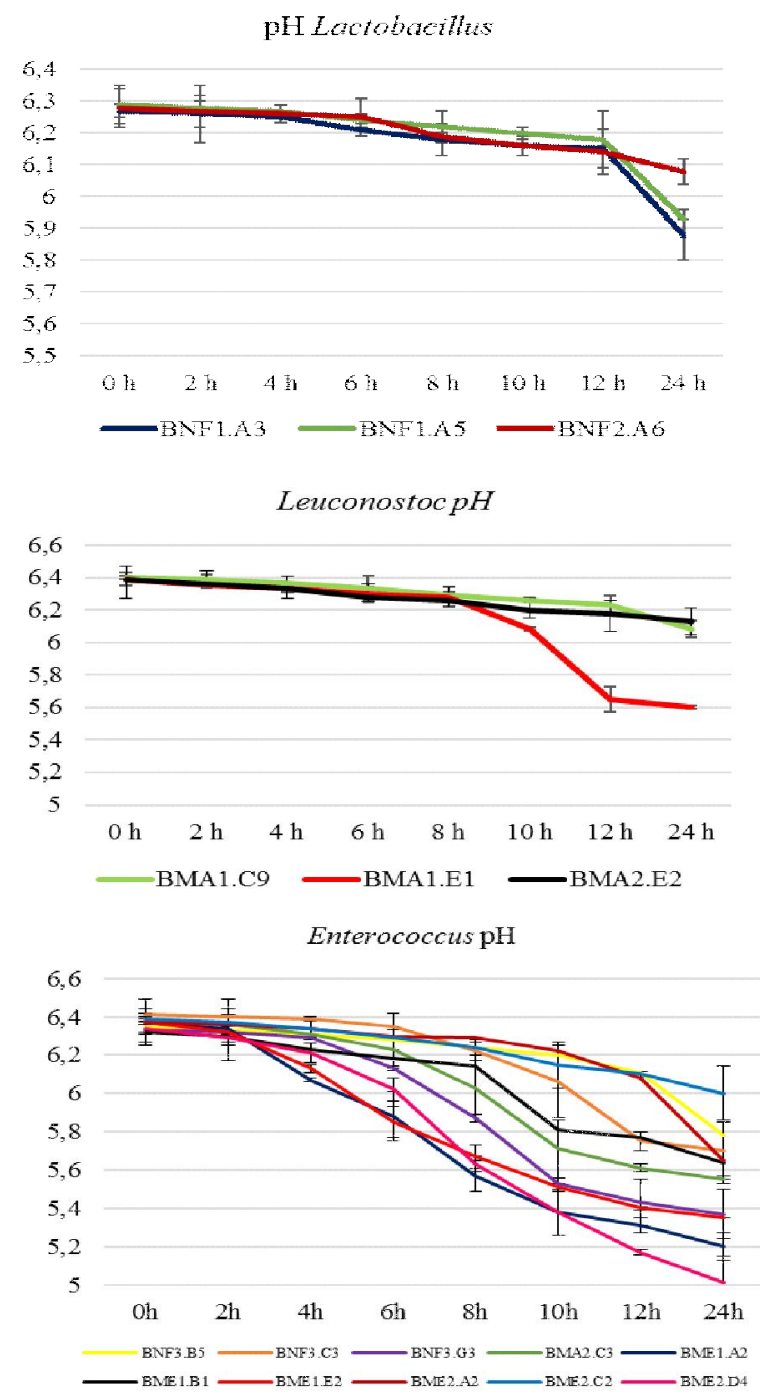

Fig 1: Acidifying activity and $\mathrm{pH}$ of 16 strains of lactic acid bacteria isolated from different sheep's milk. 
Technological Characterization of Lactic Acid Bacteria Isolated from Different Sheep's Milk

Lactic acid production by strains belonging to Lactobacillus strains was low except for the Lb plantarum (BNF1.A3) which showed moderate acidifying activity, i.e., $4.9 \mathrm{~g} / \mathrm{L}$ compared to the BNF2.A6 (Lactobacillus) strain where the amount of lactic acid produced was $3.5 \mathrm{~g} / \mathrm{L}$. Lactobacillus strains slowly metabolize lactose (Carafa et al., 2015).

The production of lactic acid by the Leuconostoc strains was significantly lower than the other two genus studied. The acidification capacity was of the order of $5.6 \mathrm{~g} / \mathrm{L}$ (BMA1.E1. Leuconostoc) and $2.9 \mathrm{~g} / \mathrm{L}$ (BMA2.E2 Ln. mesenteroïdes ssp dextranicum) and $\mathrm{pH}$ values reached with these strains vary between 6.13 and 5.60 after $24 \mathrm{~h}$ of incubation.

\section{Antimicrobial activity}

We classified the inhibitions observed in our results in 3 types depending on the dimension of the halos in low (+: 1-2 $\mathrm{mm})$ to moderate $(++: 2-4 \mathrm{~mm})$ and high $(+++:>4 \mathrm{~mm})$ (Table 1). Lactobacillus (Lb plantarum) and Enterococcus (En. durans) strains were found to have a higher antagonistic activity against pathogens. The inhibitory effect is at least weakest for Leuconostoc strains.

For Lactobacillus genus, all strains isolates showed inhibitory activity against both pathogens tested, however no supernatant showed inhibitory activity except Lactobacillus plantarum species which showed moderate inhibition against $E$. coli.

Leuconostoc genus had the lowest antimicrobial activity against $E$. coli and $P$. aeruginosa with the exception of the three $L n$. mesenteroïdes ssp dextranicum species (BMA1.A5, BMA2.B1 and BMA2.E1) which did not inhibit the indicator strains.

Most strains belonging to the Enterococcus genus have shown their inhibitory effect against both pathogens. En. durans species strongly inhibited $E$. coli with an inhibition zone exceeding $4 \mathrm{~mm}$. No supernatant was able to inhibit $P$. aeruginosa, but 6 strains of Enterococcus inhibited $E$. coli. Thus, these data demonstrate that the antagonistic activity shown against indicator pathogens allows the application of the LAB studied as bioconservatives in the production of dairy products, increasing their shelf life.

\section{CONCLUSION}

The 50 strains isolated from sheep milk showed efficient technological activities. Our LAB strains have high potential for probiotic application, with elevated production of EPS by Leuconostoc genus, high diacetyl production and also lipolytic and proteolytic activity by Lactobacillus which confers them to have a potential to be used as adjunct cultures in cheese-making. Enterococcus genus showed the most efficient antimicrobial activity against $E$. coli and $P$. aeruginosa.

High variability in technologically revealing traits was found among isolates and could be the basis for the selection of strains specifically to be used as a supplement culture in the production of dairy products and other biotechnological applications.

\section{REFERENCES}

AOAC. (2000). AOAC Official Method 996.06, Fat (total, saturated, and unsaturated) in Foods. In: Official Methods of Analysis of AOAC International. Maryland: AOAC International. (17 th ed., pp. 20-24).

Balthazara, C.F., Silva, H.L.A., Vieira, A.H., Neto, R.P.C., Cappato, L.P., Coimbra, P.T., Moraes, J., Andrade, M.M., Calado, V.M.A., Granato, D., Freitas, M.Q., Tavares, M.I.B., Raices, R.S.L., Silva, M.C., Cruz, A.G. (2017). Assessing the effects of different prebiotic dietary oligosaccharides in sheep milk ice cream. Food Res. Int. 91: 38-46.

Carafa, I., Nardin, T., Larcher, R., Viola, R., Tuohy, K. and Franciosi, E. (2015). Identification and characterization of wild lactobacilli and Pediococci from spontaneously fermented mountain cheese. Food Microbiol. 48: 123-132.

Cuffia, F., Bergamini, C.V., Hynes, E.R., Wolf, I.V. and Perotti, M.C. (2020). Evaluation of autochthonous cultures to improve the cheese flavor: A case study in hard cheese model. Food Sci. Technol. Int. 26: 173-184. https://doi.org/ 10.1177/1082013219881512.

Dahou, A.A., Bekada, A.M.A, Medjahed, M., Tahlaiti, H., Rechidi, S.N., Homrani, A. (2020). Characterization of natural lactic flora in soft cheese "Camembert of the Tessala" made from thermised milk of local breed cow "Brown of the Atlas". Asian Journal of Dairy and Food Research. 39(1): 30-34.

De-Almeida Junior, W.L.G., Ferrari, I.S., de Souza, J.V., da Silva, C.D.A., da Costa, M.M. and Dias, F.S. (2015). Characterization and evaluation of lactic acid bacteria isolated from goat milk. Food Control. 53: 96-103.

Fguiri, I., Ziadi, M., Atigui, M., Ayeb, N., Arroum, S., Assadi, M. and Khorchani, T. (2016). Isolation and characterization of lactic acid bacteria strains from raw camel milk for potential use in the production of fermented Tunisian dairy products. Int. J. Dairy Technol. 69: 103-113.

Fleming, H.P., Etchells, J.L. and Costilow, R.N. (1975). Microbial inhibition by an isolate of Pediococcus from cucumber brine. Applied and Environmental Microbiology. 30: 1040-1042.

Garabal, J.I., Rodriguez-Alonso, P. and Centeno, J.A. (2008). Characterization of lactic acid bacteria isolated from raw cows' milk cheese currently produced in Galicia (NW Spain). LWT - Food Science and Technology. 41: 1452-1458.

Giraffa, G. (2003). Functionality of enterococci in dairy products. Int. J. Food Microbiol. 88: 215e222.

Hantsis-Zacharov, E., Halpern, M. (2007). Culturable psychrotrophic bacterial communities in raw milk and their proteolytic and lipolytic traits. Appl. Environ. Microb. 73: 7162-7168.

Harris, L.J., Daeschel, M.A., Stiles, M.E. and Klaenhammer, T.R. (1989). Antimicrobial activity of lactic acid bacteria against Listeria monocytogenes. Food Biosci. 52: 384-387. https:/ /doi.org/10.4315/0362-028X-52.6.384.

Madrau, M.A., Mangia, N.P., Murgia, M.A., Sanna, M.G., Garau, G., Leccis, L., Deiana, P. (2006). Employment of autochthonous microflora in Pecorino Sardo cheese manufacturing and evolution of physicochemical parameters during ripening. International Dairy Journal. 16: 876-885.

Maina, N.H., Tenkanen, M., Maaheimo, H., Juvonen, R., Virkki, L. (2008). NMR spectroscopic analysis ofexopolysaccharides produced by Leuconostoc citreum and Weissella confusa. Carbohyd. Res. 343: 1446-1455. 
Nieto-Arribas, P., Sesena, S., Poveda, J.M., Palop, L. and abezas, L. (2010). Genotypic and technological characterization of Leuconostoc isolates to be used as adjunct starters in Manchego cheese manufacture. Food Microbiol. 27: 8593.

Nikolic, M., Terzic-Vidojevic, A., Jovcic, B., Begovic, J., Golic, N. and Topisirovic, L. (2008). Characterization of lactic acid bacteria isolated from Bukuljac, a homemade goat's milk cheese. Int. J. Food Microbiol. 122: 162-170.

Patil, P., Wadehra, A., Munjal, K. and Behare, P. (2015). Isolation of exopolysaccharides producing lactic acid bacteria from dairy products. Asian Journal of Dairy and Food Research. 34(4): 280-284.
Ribeiro, S.C., Coelho, M.C., Todorov, S.D., Franco, B.D., Dapkevicius, M.L. and Silva, C.C. (2014). Technological properties of bacteriocin-producing lactic acid bacteria isolated from Pico cheese an artisanal cow's milk cheese. J. Appl. Microbiol. 116: 573-585.

Saha, P., Ray, P.R., Hazra, T. (2017). Evaluation of quality and stability of Chhana whey beverage fermented with lactic acid bacteria. Asian Journal of Dairy and Food Research. 36(2): 112-116.

Shehata, M.G., El Sohaimy, S.A., El-Sahn, M.A. and Youssef, M.M. (2016). Screening of isolated potential probiotic lactic acid bacteria for cholesterol lowering property and bile salt hydrolase activity. Ann. Agric. Sci. 61: 65-75. https:// doi.org/10.1016/j. aoas.2016.03.001. 